\title{
Handgrip strength and its relation to isokinetic dynamometry in COPD
}

\author{
Força de Preensão Palmar e sua relação com dinamometria \\ isocinética na DPOC
}

\author{
Marisandra Flesch Nunes $\mathbb{D}^{D}$, Bruno Barcellos Hervé (D), Janice Luísa Lukrafka $\mathbb{D}^{\text {, }}$ \\ Mariane Borba Monteiro
}

Universidade Federal de Ciências da Saúde de Porto Alegre (UFCSPA), Porto Alegre, RS, Brazil

\begin{abstract}
Introduction: Muscle dysfunction is one of the major changes found in chronic obstructive pulmonary disease (COPD) and associated with loss of functionality, morbidity and mortality. Objective: correlate two strength assessment methods: manual dynamometry for handgrip strength and isokinetic dynamometry for quadriceps strength in patients with COPD, and assess the body mass index, airflow obstruction, dyspnea, and exercise capacity (BODE), quality of life and muscle strength. Method: twenty-five patients with moderate to very severe COPD were evaluated by pulmonary function parameters, anthropometric variables, functional capacity, via the six-minute walk test, dyspnea, applying the modified Medical Research Council (mMRC) scale, BODE, quality of life, using the Saint George's Respiratory Questionnaire (SGRQ), handgrip strength with manual dynamometer and quadriceps force using an isokinetic dynamometer. Muscle strength was assessed with a manual portable dynamometer and isokinetic dynamometer. For statistical analysis, ANOVA with Bonferroni's post-test, the chi-squared test and Pearson's correlation coefficient were used. Results: There was a strong correlation between the strength measurements and the two instruments (torque and quadriceps extension power with right handgrip strength: $r=0.74 ; p<0.001$ ). The patients
\end{abstract}

*MFN: BS, e-mail: mari.flesch@yahoo.com.br BBH: MS, e-mail: bbherve@gmail.com JLL: PhD, e-mail:janicet@ufcspa.edu.br MBM: PhD, e-mail:marianem@ufcspa.edu.br 
classified as very severe exhibited worse performance in the strength tests when compared to the moderate group, albeit with no statistically significant difference. Conclusion: In muscle strength measurements, a strong correlation was detected between the isokinetic dynamometer for quadriceps and the manual dynamometer for handgrip strength. These findings indicate that, in clinical practice, the manual dynamometer for handgrip strength could be used to assess peripheral muscle strength in patients with COPD.

Keywords: Chronic Obstructive Pulmonary Disease. Muscle Strength. Muscle Strength Dynamometer.

\section{Resumo}

Introdução: Disfunção muscular é uma das principais alterações encontradas na Doença Pulmonar Obstrutiva Crônica (DPOC), estando relacionada com perda da funcionalidade, morbidades e mortalidade. Objetivo: Correlacionar dois métodos de avaliação de força: dinamometria manual para força de preensão palmar (FFP) e dinamometria isocinético para força de quadríceps em pacientes com DPOC, e avaliar dispneia, Body mass index, airway Obstruction, Dyspnea, and Exercise capacity (BODE), qualidade de vida e força muscular. Método: Foram avaliados 25 pacientes com DPOC moderada a muito severa quanto a espirometria e antropometria; capacidade funcional através da distância percorrida no teste de caminhada de seis minutos (DTC6); dispneia através da escala modificada Medical Research Council; BODE; e qualidade de vida através do Saint George's Respiratory Questionnaire. A força muscular foi avaliada através de dinamômetro portátil manual e dinamômetro isocinético. Para estatística utilizou-se ANOVA e pós-teste de Bonferroni, teste de Qui-quadrado e Coeficiente de Correlação de Pearson. Resultados: Houve correlação entre medidas de força com os dois instrumentos (torque e potência de extensão do quadríceps com FPP direita: $r=0,74 ; p<0,001$ ). Não houve diferença nos testes de força em relação à gravidade da doença. Além disso, o DTC6 não mostrou diferença significativa entre os grupos e a qualidade de vida mostrou-se pior no grupo muito severo, tendo diferença significativa em relação ao grupo moderado. Conclusão: Foi encontrada forte correlação entre as medidas de força realizadas com dinamômetro isocinético para o quadríceps e dinamômetro manual para FPP. Esses achados indicam que, na prática clínica, o dinamômetro manual pode ser utilizado para avaliação da musculatura periférica em pacientes com DPOC.

Palavras-chave: Doença Pulmonar Obstrutiva Crônica. Força Muscular. Dinamômetro de Força Muscular.

\section{Introduction}

Chronic obstructive pulmonary disease (COPD) is a common, preventive and treatable condition, characterized by limited airflow due to structural changes in the airways and lung parenchyma, generally caused by exposure to harmful particles or gases. It is considered one of the primary causes of death and disability, mainly in older adults, and estimates rank it among the four leading causes of death worldwide by 2030 [1].

Respiratory symptoms are only one of multiple complications of the disease, since, with exacerbation, other morbidities and systemic changes have a negative effect on the quality of life of these patients. Muscle dysfunction is one of the main changes related to loss of functionality, in addition to being an independent predictor of morbidity and mortality. The decline in muscle mass occurs in 4 to $39 \%$ of these patients, depending on how it is assessed, and derives from an array of structural and metabolic factors, such as changes in fiber type, bioenergy, capillarizations, imbalance between protein synthesis and degradation, disuse, use of systemic corticoids, hypoxia and hypercapnia, muscle remodeling and mitochondrial abnormalities [2,3]. It is believed that systemic inflammation, associated or not with pre-existing local lung inflammation, as well as oxidative stress, also play an essential role in this extrapulmonary manifestation of COPD [4].

Irrespective of the factors that influence the muscle strength of patients with COPD, its assessment and monitoring are important. Among the resources available, the isokinetic dynamometer is considered the gold standard to determine muscle strength and is therefore widely used in scientific circles to quantify the degree of peripheral muscle dysfunction in individuals with 
COPD [5]. However, this is a costly instrument that is not widely available in clinical practice. Thus, alternative assessment methods have been developed. In a systematic review, Stark et al. [5] identified a positive correlation in muscle strength between the portable and isokinetic dynamometer, concluding that the former could be considered a valid and reliable instrument in clinical practice.

Portable strength measurement models are widely used in clinical practice. However, it has not been established whether the manual handgrip model could be used as an alternative to assess patients with COPD. As such, the primary aim of this study was to determine the relation between strength measurements obtained with an isokinetic dynamometer and handgrip isometric dynamometer. The secondary aim was to evaluate the feeling of dyspnea, BODE index, changes in functional capacity and quality of life, as well as peripheral muscle strength in the different stages of the disease.

\section{Method}

This is a cross-sectional analytical study involving individuals of both sexes, aged between 50 and 65 years, diagnosed with COPD, recruited at the Center of Pulmonary Rehabilitation of the Pereira Filho Pavilion and the Pneumonology OutpatientFacility of Santa Clara Polyclinic belonging to the Santa Casa de Misericórdia Sisterhood of Porto Alegre (ISCMPA). The patients were selected between January 2016 and August 2017 and sample recruitment occurred at the Functional Rehabilitation Laboratory of the Federal University of Health Sciences of Porto Alegre (UFCSPA).

The present study was approved by the research ethics committees of UFCSPA - protocol number 722.577 and ISCMPA - protocol number 683.031. Included were individuals with moderate to severe COPD, able to undergo the proposed assessmenttests. COPD was previously diagnosed according to the criteria established by the Global Initiative for Chronic Obstructive Lung Disease (GOLD), confirmed by the pulmonary function test [6].

Exclusion criteria were dependence on supplementary oxygen; individuals diagnosed with acute or chronic disease associated with ventilatory or musculoskeletal repercussion; presence of specific acute disease of the airways or exacerbation of COPD in the four weeks prior to data collection. The eligible patients who agreed to participate provided written informed consent.
Participants were assessed in terms of clinical variables such as smoking, professional risk and time since diagnosis, and anthropometric variables by body mass index (BMI). Physical activity was evaluated using the International Physical Activity Questionnaire Short Form (IPAQ-SF).

The pulmonary function tests were conducted using an MK8 spirometer (Microlab. San Diego, USA). Forced expiratory volume in 1 second (FEV1), forced vital capacity (FVC) and the FEF1/FVC ratio were measured. The subjects were then instructed to perform forced maneuvers by blowing through a disposable nozzle, at the researcher's command. Three maneuvers were carried out and the procedure followed American Thoracic Society (ATS) recommendations.

The 6-minute walk test (6MWT) was conducted to assess functional capacity. Participants were asked to walk as far as possible for 6 minutes; they were allowed to pause, if necessary, but the stopwatch continued to record. Standard phrases of encouragement were used every minute. The test was performed on a 30-meter-long flat corridor at ISCMPA. The following parameters were evaluated before and after the test: respiratory rate, heart rate, blood pressure, feeling of dyspnea and lower limb fatigue, as well as peripheral oxygen saturation. The distance covered was recorded at the end of the six minutes. The test was applied only once, according to American Thoracic Society (ATS) recommendations.

Based on the data obtained in the 6MWT, pulmonary function test, BMI and feeling of dyspnea using the mMRC, the body mass index, airflow obstruction, dyspnea, and exercise capacity (BODE) index was calculated.

Upper limb muscle strength was assessed by handgrip strength (HGS) using the EH101 E-clear electronic manual dynamometer (China). During the measurements, the individuals were seated with the arm being assessed adducted parallel to their trunk, elbow flexed at 90 degrees and forearm and wrist in the neutral position. Three measurements were taken at least one minute apart, alternating between the dominant and non-dominant sides. Three values were recorded, and the highest dominant side value was used, provided it did not differ by more than $10 \%$ from the other results $[7,8]$.

Quadriceps strength was measured using the Biodex System 4 Pro isokinetic dynamometer (Biodex Medical Systems. NY, USA). The equipment, which was attached to the muscle group to be tested, provided peak strength (measured in pounds and then converted into Newtons), that is, an objective quantification of maximum muscle strength. Seven maximum contractions were performed 
approximately 10 seconds apart, and the highest of three reproducible maneuvers was used, provided it did not differ by more than $5 \%$. In order to measure knee extensor strength (specifically the femoral quadriceps), the patients sat erect, with hands on their thighs and the assessor standing in front of them. The test started with the assessor gradually applying force at three different times: the first with the patient initiating muscle contraction against the device and the assessor's hands, the second increasing the force and the third exerting the maximum possible contraction, that is, an isometric contraction, until reaching a range of motion of approximately $30^{\circ}$ of knee extension from an initial position of 90 . . The patient was asked to not make any compensation during measurements, and the time between each measure did not exceed 10 seconds. All the patients received standard verbal encouragement [9 - 11].

The protocols could be suspended if the individual experienced dizziness, a hypertensive crisis (values above $140 / 90 \mathrm{mmHg}$ ) or if peripheral oxygen saturation was less than $80 \%$. However, no complications occurred during collections. In addition, all the patients were monitored by duly trained researchers during the activities.

The Saint George's Respiratory Questionnaire (SGRQ) was applied between the muscle strength and power tests. The SGRQ is a disease-specific instrument designed to measure the impact on overall health, daily life and perceived well-being of patients with an obstructive disease of the airways. It encompasses the symptom, activity and social impact domains of the disease. Each domain is scored between 0 and 100, with the highest scores indicating more limitations. The questionnaire is self-applied and validated in Brazil.

Sample size was calculated based on Cortopassi [12], using the Biostat program, version 5.3, in which a confidence level of $95 \%$, acceptable difference of 0.05 and coefficient of variation of $20 \%$ were adopted, indicating a sample of 24 subjects.

Data normality was verified by the Shapiro-Wilk test. The data were presented as mean \pm standard deviation and the groups compared using analysis of variance (ANOVA), followed by Bonferroni's post-hoc test. The categorical/ordinal data were presented as absolute (relative) frequency and the proportions compared by applying the chi-squared test. The correlations between continuous variables were determined by Pearson's correlation coefficient. A significance level of $\mathrm{p} \leq 0.05$ was set for all the tests and the Statistical Package for the Social Sciences 20.0 (SPSS Inc., USA) was used.

\section{Results}

A total of 25 patients with COPD were assessed, most classified as very severe. Only one patient did not participate in the lung rehabilitation program. The sample characteristics are presented in Table 1.

Table 1 - Sample Characterization

\begin{tabular}{|c|c|c|c|c|}
\hline & Moderate $(n=8)$ & Severe $(n=7)$ & $\begin{array}{l}\text { Very Severe } \\
(n=10)\end{array}$ & All $(n=25)$ \\
\hline Sex (male/female) & $3 / 5$ & $2 / 5$ & $4 / 6^{\star \#}$ & $9 / 16$ \\
\hline Age (years) & $73.50 \pm 10.60$ & $69.71 \pm 8.07$ & $57.50 \pm 7.87^{\star \#}$ & $66.04 \pm 11.19$ \\
\hline Height (cm) & $164.25 \pm 8.69$ & $160.28 \pm 8.30$ & $163.80 \pm 10.88$ & $162.96 \pm 9.30$ \\
\hline Weight (kg) & $75.50 \pm 9.19$ & $69.30 \pm 16.53$ & $59.69 \pm 17.70$ & $67.44 \pm 16.06$ \\
\hline BMI $\left(\mathrm{kg} / \mathrm{m}^{2}\right)$ & $27.95 \pm 2.32$ & $26.91 \pm 6.23$ & $21.98 \pm 4.71^{*}$ & $25.27 \pm 5.22$ \\
\hline BODE & $2.25 \pm 0.5$ & $3.25 \pm 1.89$ & $5.28 \pm 1.79^{\star \#}$ & $3.96 \pm 2.28$ \\
\hline $\mathrm{mMRC}$ & $1.87 \pm 0.83$ & $1.28 \pm 1.38$ & $2.70 \pm 1.41$ & $2.04 \pm 1.33$ \\
\hline Smoker (yes/ex) & $0 / 8$ & $1 / 6$ & $0 / 10$ & $1 / 24$ \\
\hline Cigarettes/day & $26.85 \pm 11.65$ & $24.00 \pm 16.54$ & $23.80 \pm 13.94$ & $24.75 \pm 13.59$ \\
\hline $\begin{array}{l}\text { Number of years } \\
\text { smoking }\end{array}$ & $36.00 \pm 13.02$ & $37.85 \pm 13.69$ & $30.70 \pm 8.20$ & $34.33 \pm 11.39$ \\
\hline $\begin{array}{l}\text { Number of years without } \\
\text { smoking }\end{array}$ & $15.00 \pm 12.23$ & $11.05 \pm 12.43$ & $6.41 \pm 4.62$ & $10.23 \pm 9.93$ \\
\hline PR (no/yes & $0 / 7$ & $1 / 6$ & $0 / 8$ & $1 / 21$ \\
\hline $\begin{array}{l}\text { Rehabilitation time } \\
\text { (months) } \dagger\end{array}$ & $9.5(67.03)$ & $1.60(26.45)$ & $3.00(11.00)$ & $2.00(12.00)$ \\
\hline
\end{tabular}

Note: BMI: body mass index; BODE: body mass index, airway obstruction, dyspnea, and exercise capacity; mMRC: modified Medical Research Council; PR: pulmonary rehabilitation. Data presented as mean \pm standard deviation or absolute frequency. $†$ Indicates a variable presented as median (interquartile interval). * Indicates a significant difference compared to the control group $(p<0.05)$. \# Indicates a significant difference compared to the severe group $(p<0.05)$. 
Table 2 presents lung function, distance covered in the 6MWT and quality of life data. Performance on the walk test showed no significant intergroup difference in relation to disease severity.
Quality of life was worse in the very severe group $(60.20 \pm 17.17 \%)$, with a significant difference in relation to the moderate group $(37.37 \pm 13.55 \%$. $\mathrm{p}<0.001$ ).

Table 2 - Lung function, functional capacity and quality of life of the patients

\begin{tabular}{|c|c|c|c|c|}
\hline & Moderate $(n=8)$ & Severe $(n=7)$ & $\begin{array}{c}\text { Very Severe } \\
(n=10)\end{array}$ & All $(n=25)$ \\
\hline FEV1 (L) & $1.36 \pm 0.37$ & $0.93 \pm 0.24^{*}$ & $0.51 \pm 0.13^{\star \#}$ & $0.90 \pm 0.44$ \\
\hline FEV1 \%Pred & $61.75 \pm 9.43$ & $40.14 \pm 4.45^{\star}$ & $18.60 \pm 5.37^{\star \#}$ & $38.44 \pm 19.69$ \\
\hline $\mathrm{FVC}(\mathrm{L})$ & $2.33 \pm 0.67$ & $1.66 \pm 0.54$ & $1.36 \pm 0.47^{\star \#}$ & $1.76 \pm 0.68$ \\
\hline FVC \%Pred & $82.62 \pm 11.08$ & $55.85 \pm 10.85^{\star}$ & $39.00 \pm 8.89^{\star \#}$ & $57.68 \pm 21.18$ \\
\hline 6MWT Pred (m) & $435.62 \pm 63.84$ & $458.42 \pm 54.88$ & $576.10 \pm 69.12$ & $498.2 \pm 90.45$ \\
\hline 6MWT (m) & $452.75 \pm 103.83$ & $424.00 \pm 124.46$ & $321.20 \pm 105.51$ & $392.80 \pm 121.69$ \\
\hline SGRQ (\%) & $37.37 \pm 13.55$ & $45.42 \pm 18.76$ & $60.20 \pm 17.17^{*}$ & $48.76 \pm 18.79$ \\
\hline
\end{tabular}

Note: Data presented as mean \pm standard deviation. FEV1: Forced expiratory volume in 1 second; FVC: Forced vital capacity; 6MWT: 6-minute walk test; SGRQ: Saint George's Respiratory Questionnaire; Pred: Predicted. * Indicates a significant difference compared to the control group $(p<0.001)$. \# Indicates a significant difference compared to the severe group $(p<0.001)$.

Table 3 presents the HGS and quadriceps results. All the patients were right-handed. No statistically significant differences were observed between the different disease severities.

Table 3 - Muscle strength assessment

\begin{tabular}{lcccc} 
& Moderate $(\mathbf{n = 8})$ & Severe $(\mathbf{n = 7})$ & $\begin{array}{c}\text { Very Severe } \\
(\mathbf{n}=\mathbf{1 0})\end{array}$ & All $(\mathbf{n = 2 5})$ \\
R HGS (kgf) & $27.13 \pm 6.24$ & $27.92 \pm 8.22$ & $30.04 \pm 12.35$ & $28.52 \pm 9.33$ \\
L HGS (kgf) & $24.65 \pm 5.30$ & $25.15 \pm 8.97$ & $26.48 \pm 10.64$ & $25.52 \pm 8.45$ \\
Ext Torque (N.m) & $98.62 \pm 33.54$ & $76.64 \pm 22.18$ & $82.67 \pm 38.41$ & $86.08 \pm 32.98$ \\
Flex Torque (N.m) & $46.45 \pm 14.86$ & $36.80 \pm 9.35$ & $37.75 \pm 14.31$ & $40.26 \pm 13.49$ \\
Ext Power Ext (watts) & $58.47 \pm 24.79$ & $43.00 \pm 17.63$ & $47.65 \pm 25.30$ & $49.81 \pm 23.18$ \\
Flex Power Flex (watts) & $27.45 \pm 11.22$ & $19.14 \pm 5.98$ & $21.25 \pm 10.70$ & $22.64 \pm 10.04$ \\
\hline
\end{tabular}

Note: Data presented as mean \pm standard deviation. HGS: Handgrip strength; Ext: Extensors; Flex, Flexors. * All the patients were righthanded. $\mathrm{R}=$ right, $\mathrm{L}=$ left

Analysis of upper limb muscle strength showed a positive correlation with quadriceps. The following correlations were observed in the left upper limb between HGS and extension torque $(r=0.79)$; flexion torque $r=0.72)$; extension power $(r=0.77)$; and flexion power $(r=0.72)$, all with $\mathrm{p}<0.001$. In the left upper limb, correlations were also observed between HGS and extension torque ( $\mathrm{r}=0.74)$; flexion torque $(\mathrm{r}=0.67)$; extension power $(\mathrm{r}=0.74)$; and flexion power $(r=0.69)$, all with $p<0.001$. Figures 1 and 2 show the strong correlations between these variables (Figures 1 and 2). 

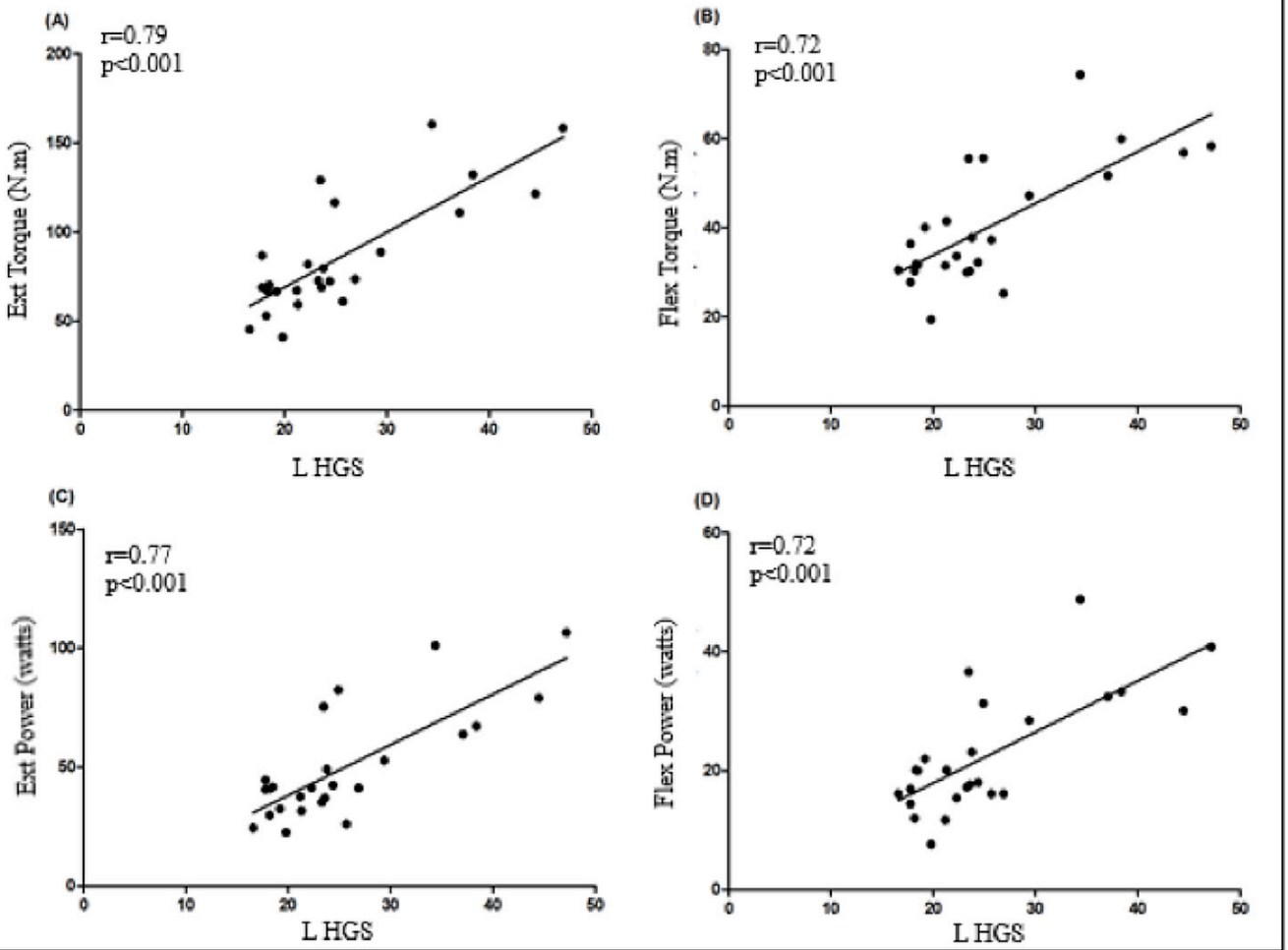

Figure 1 - Correlation between quadriceps torque/power (dominant side) and left handgrip strength. Note: Ext: extensors; Flex: flexors; L HGS: Left handgrip strength. Data obtained by Pearson's correlation.
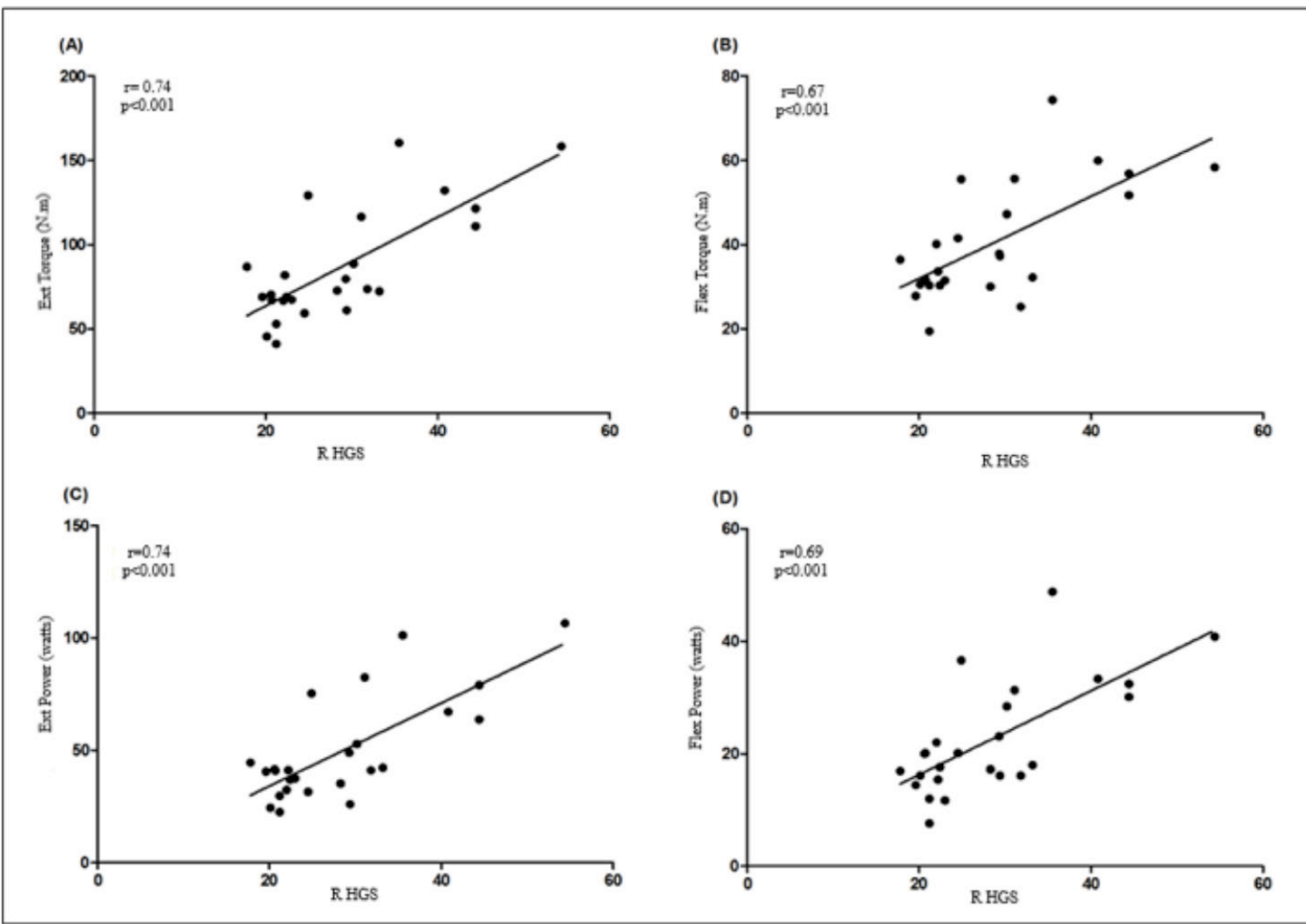

Figure 2 - Correlation between quadriceps torque/power (dominant side) and right handgrip strength. Note: Ext: extensors; Flex: flexors; R HGS: Right handgrip strength. Data obtained by Pearson's correlation. 


\section{Discussion}

In the present study, handgrip strength showed a strong correlation with quadriceps muscle strength. To the best of our knowledge, no studies have correlated HGS with quadriceps strength, assessed with the same instruments in patients with COPD. Considering that isokinetic dynamometry is the gold standard for analyzing strength and that correlations with the manual dynamometer were all strong, it can be inferred that this may be an efficient resource in clinical practice to determine the overall muscle strength of patients.

Studies indicate that with the advance of the disease, some patients with COPD develop migraine headaches, currently a predictor of risk, irrespective of mortality, in addition to the negative impact on tolerance and respiratory capacity $[13,14]$. Jones et al. assessed 622 patients with stable COPD and found that around 15\% of the sample exhibited sarcopenia, were significantly older, manifested a more severe form of the disease, and displayed decreased quadriceps strength, functional capacity and quality of life [15]. As such, assessment of peripheral muscle strength in patients with COPD is essential, given that it is related to factors such as exercise intolerance, difficulty in performing activities of daily living, worse quality of life and early mortality. In the context of pulmonary rehabilitation, assessment of strength is also useful for both exercise prescription and quantification of advances or losses after exacerbation periods or hospitalization [16 - 20].

In the last decade, several studies have demonstrated a decline in peripheral muscle strength assessed by HGS using a portable dynamometer. In addition, there is a positive association between HGS and other clinical and functional parameters for this population, such as FEV1, 6MW distance and exacerbation [12, 21 - 23]. However, its role in reproducing reliable strength data, and the association with muscle strength and torque have not been fully explored, considering the portable dynamometer as a resource to substitute more burdensome and complex equipment. In the present study, a strong positive association was found between HGS and the isokinetic test, in patients with different severities of COPD.

A recent review by Bui et al. underscores the loss in peripheral muscle strength especially of the lower limbs, in patients with COPD, and the most appropriate instruments to assess it. These include fixed strain gauge systems for isometric contraction, computerized dynamometers for isometric and isokinetic assessment, the one-repetition maximum test and portable handgrip gauges [24]. The isokinetic dynamometer, the gold standard method to measure muscle strength, has been widely used in scientific circles to quantify the degree of peripheral muscle strength in individuals with COPD [5]. However, it is a costly instrument that is not readily available in clinical practice. The findings of the present study suggest that HGS can be used as an alternative assessment since a strong positive correlation was found between the two measurement instruments.

The muscle groups involved in locomotion generally exhibit greater changes when compared with respiratory muscles or the upper limbs. The muscles of these segments seem to be better preserved, exhibiting fewer structural and functional alterations when compared to the lower limbs [7,25], which could explain the absence of a correlation between HGS and quadriceps strength. However, this did not occur in the present study, given that even at different declining velocities, both muscle groups showed an association between loss of quadriceps strength and HGS. Thus, the muscle strength of patients with COPD can be assessed using handgrip strength, a safe, practical, and low-cost method.

As secondary objectives of the present study, the patients classified as very severe showed a significantly lower BMI and significantly higher BODE than their moderate and severe counterparts, corroborating the trend between lower weight and greater risk of mortality proportional to disease severity. We did not assess sarcopenia or find the same influence of these variables on disease severity assessed by the degree of obstruction, likely due to the small sample size in each group.

Although fat distribution and the decline in lean mass occurred differently in patients with COPD when compared to healthy individuals, it was not global. The decrease in lower limb muscle strength, primarily in the femoral quadriceps, is more marked in patients with COPD than in healthy individuals $[14,26]$. In the present study, despite the worse muscle performance of individuals with severe or very severe disease, the difference was not statistically significant, as reported by Costa et al. [27]. It is important to underscore that the very severe patients in our study were significantly younger than the others, which may have influenced this result.

The functional capacity of the patients, assessed by the 6MWT, was lower than normal in the different disease severities. The very severe patients walked an average of $321.20 \pm 105.51 \mathrm{~m}$, considered a predictor of mortality and hospitalization $[28,29]$. Although the 
distance covered was smaller in this group of patients, there was no significant intergroup difference in disease severity, which may have occurred due to the small sample size. However, Kovarik M et al. [8] report that the HGS test is more related to the clinical status and prognosis of the patient than the distance covered in the 6MWT. This underscores the importance of evaluating other parameters, in addition to functional capacity and degree of obstruction to define severity, including data such as the BODE index and HGS [30].

Silva et al. conducted a study involving 34 patients with COPD, assessing HGS using a portable isometric dynamometer. The authors found moderate correlations between HGS (dominant and non-dominant side) and distance covered in the 6MWT, as well as weak inverse correlations between HGS (dominant and non-dominant side) and the BODE index, concluding that in the sample studied, patients with lower HGS covered shorter distances in the 6MWT and obtained higher BODE index scores, which represent worse survival. Although this was not the aim of the present study, the findings of Silva et al. reinforce the relevance of using HGS in the clinical routine for these patients [30]. Corroborating its importance, Felipe Cortopassi et al., studied 27 patients with COPD and 12 healthy subjects, observing a correlation between HGS and dynamic hyperinflation (HD) in COPD. The inspiratory capacity/ total lung capacity ratio (IC/TLC) is an independent factor associated with HGS [12]. Given the frequent difficulty in gaining access to plethysmography examinations to assess HD with TLC, HGS assessment becomes a useful tool.

The present study exhibits a number of limitations, such as the fact that most patients participated in a rehabilitation program. Thus, it cannot be inferred that muscle strength behavior is the same in sedentary patients with COPD, given that an exercise program can potentially reverse or at least stabilize muscle changes. Healthy individuals with age and body composition similar to the sample were not assessed to compare their performance with that of COPD patients in the different stages of the disease. It is important to underscore that a larger sample size could be used in each subgroup, according to severity, for a stratified analysis.

Nevertheless, given the correlation obtained between the two tests proposed, we recommend the use of a portable dynamometer to determine handgrip strength, producing an adequate assessment of muscle strength in the routine evaluation and follow-up of patients with COPD. The method selected to correlate with the gold standard is low cost and easy to apply.

\section{Conclusion}

In conclusion, we found a positive correlation between HGS assessment and quadriceps strength. In addition, patients with COPD showed a decline in functional capacity, muscle strength and quality of life.

\section{References}

1. Vogelmeier CF, Criner GJ, Martinez FJ, Anzueto A, Barnes PJ, Bourbeau J, et al. Global Strategy for the Diagnosis, Management, and Prevention of Chronic Obstructive Lung Disease 2017 Report. GOLD Executive Summary. Am J Respir Crit Care Med. 2017;195(5):557-82.

2. Abdulai RM, Jensen TJ, Patel NR, Polkey MI, Jansson P, Celli BR, et al. Deterioration of Limb Muscle Function during Acute Exacerbation of Chronic Obstructive Pulmonary Disease. Am J Respir Crit Care Med. 2018;197(4):433-49.

3. Gea J, Pascual S, Casadevall C, Orozco-Levi M, Barreiro E. Muscle dysfunction in chronic obstructive pulmonary disease: update on causes and biological findings. J Thorac Dis. 2015;7(10):E418-38.

4. Jaitovich A, Barreiro E. Skeletal Muscle Dysfunction in Chronic Obstructive Pulmonary Disease. What we know and can do for our patients. Am J Respir Crit Care Med. 2018;198(2):175-186. Erratum in: Am J Respir Crit Care Med. 2018;198(6):824-5.

5. Stark T, Walker B, Phillips JK, Fejer R, Beck R. Handheld dynamometry correlation with the gold standard isokinetic dynamometry: a systematic review. PM R. 2011;3(5):472-9.

6. GOLD: Global Strategy for the Diagnosis, Management, and Prevention of chronic obstructive lung disease 2020 Report [cited 2020 Feb 3]. Available from: https://tinyurl.com/y7uco56c

7. Kaymaz D, Candemir İC, Ergün P, Demir N, Tașdemir F, Demir P. Relation between upper-limb muscle strength with exercise capacity, quality of life and dyspnea in patients with severe chronic obstructive pulmonary disease. Clin Respir J. 2018;12(3):1257-63. 
8. Kovarik M, Joskova V, Patkova A, Koblizek V, Zadak Z, Hronek M. Hand grip endurance test relates to clinical state and prognosis in COPD patients better than 6-minute walk test distance. Int J Chron Obstruct Pulmon Dis. 2017;12:3429-35.

9. Rodrigues FM, Demeyer H, Hornikx M, Camillo CA, CalikKutukcu E, Burtin C, et al. Validity and reliability of strain gauge measurement of volitional quadriceps force in patients with COPD. Chron Respir Dis. 2017;14(3):289-97.

10. Bui KL, Mathur S, Dechman G, Maltais F, Camp P, Saey D. Fixed Handheld Dynamometry Provides Reliable and Valid Values for Quadriceps Isometric Strength in people with Chronic Obstructive Pulmonary Disease: A Multicenter Study. Phys Ther. 2019;99(9):1255-67.

11. Lesnak J, Anderson D, Farmer B, Katsavelis D, Grindstaff TL. Validity of hand-held dynamometry in measuring quadriceps strength and rate of torque development. Int J Sports Phys Ther. 2019;14(2):180-7.

12. Cortopassi F, Celli B, Divo M, Pinto-Plato V. Longitudinal changes in handgrip strength, hyperinflation, and 6-minute walk distance in patients with COPD and a control group. Chest. 2015;148(4):986-94.

13. Kwan HY, Maddocks M, Nolan CM, Jones SE, Patel S, Barker RE, et al. The prognostic significance of weight loss in chronic obstructive pulmonary disease-related cachexia: a prospective cohort study. J Cachexia Sarcopenia Muscle. 2019;10(6):1330-8.

14. McDonald MN, Wouters EFM, Rutten E, Casaburi R, Rennard SI, Lomas DA, et al. It's more than low BMI: prevalence of cachexia and associated mortality in COPD. Respir Res. 2019;20(1):100.

15. Jones SE, Maddocks M, Kon SS, Canavan JL, Nolan CM, Clark AL, et al. Sarcopenia in COPD: prevalence, clinical correlates and response to pulmonary rehabilitation. Thorax. 2015;70(3):213-8.

16. Xavier RF, Pereira ACAC, Lopes AC, Cavalheri V, Pinto RMC, Cukier A, et al. Identification of Phenotypes in People with COPD: Influence of Physical Activity, Sedentary Behaviour, Body Composition and Skeletal Muscle Strength. Lung. 2019;197(1):37-45.

17. McNamara RJ, Houben-Wilke S, Franssen FME, Smid DE, Vanfleteren LEGW, Groenen MTJ, et al. Determinants of functional, peak and endurance exercise capacity in people with chronic obstructive pulmonary disease. Respir Med. 2018;138:81-7.
18. Brandt J, Spruit MA, Hansen D, Franssen FM, Derave W, Sillen MJ, et al. Changes in lower limb muscle function and muscle mass following exercise-based interventions in patients with chronic obstructive pulmonary disease: A review of the English-language literature. Chron Respir Dis. 2018;15(2):182-219.

19. Zeng Y, Jiang F, Chen Y, Chen P, Cai S. Exercise assessments and trainings of pulmonary rehabilitation in COPD: a literature review. Int J Chron Obstruct Pulmon Dis. 2018;13:2013-23.

20. Marillier M, Bernard AC, Vergès S, Neder JA. Locomotor Muscles in COPD: The Rationale for Rehabilitative Exercise Training. Front Physiol. 2020;10:1590.

21. Martinez CH, Diaz AA, Meldrum CA, McDonald MN, Murray S, Kinney GL, et al. COPDGene Investigators. Handgrip Strength in Chronic Obstructive Pulmonary Disease. Associations with Acute Exacerbations and Body Composition. Ann Am Thorac Soc. 2017;14(11):1638-45.

22. Burtin C, Riet GT, Puhan MA, Waschki B, Garcia-Aymerich J, Pinto-Plata V, et al. Handgrip weakness and mortality risk in COPD: a multicentre analysis. Thorax. 2016;71(1):86-7.

23. Strandkvist V, Andersson M, Backman $\mathrm{H}$, Larsson A, Stridsman RN, Lindberg A. Hand grip strength is associated with fatigue among men with COPD: epidemiological data from Northern Sweden. Physiother Theory Pract. 2020;36(3):408-16

24. Bui KL, Nyberg A, Rabinovich R, Saey D, Maltais F. The Relevance of Limb Muscle Dysfunction in Chronic Obstructive Pulmonary Disease: A Review for Clinicians. Clin Chest Med. 2019;40(2):367-83.

25. Maltais F, Decramer M, Casaburi R, Barreiro E, Burelle Y, Debigaré R, et al. An official American Thoracic Society/ European Respiratory Society statement: update on limb muscle dysfunction in chronic obstructive pulmonary disease. Am J Respir Crit Care Med. 2014;189(9):e15-62.

26. Morakami FK, Morita AA, Bisca GW, Felcar JM, Ribeiro $\mathrm{M}$, Furlanetto KC, et al. Can the six-minute walk distance predict the occurrence of acute exacerbations of COPD in patients in Brazil? J Bras Pneumol. 2017;43(4):280-4.

27. Costa TM, Costa FM, Moreira CA, Rabelo LM, Boguszewski CL, Borba VZ. Sarcopenia in COPD: relationship with COPD severity and prognosis. J Bras Pneumol. 2015;41(5):415-21. 
28. Perez T, Deslée G, Burgel PR, Caillaud D, Le Rouzic O, Zysman M, et al. Predictors in routine practice of 6-min walking distance and oxygen desaturation in patients with COPD: impact of comorbidities. Int J Chron Obstruct Pulmon Dis. 2019;14:1399-410.

29. Fermont JM, Masconi KL, Jensen MT, Ferrari R, Di Lorenzo VAP, Marott JM, et al. Biomarkers and clinical outcomes in COPD: a systematic review and meta-analysis. Thorax. 2019;74(5):439-46.
30. Silva ALG, Garmatz E, Goulart CL, Carvalho LL, Cardoso DM, Paiva DN. Handgrip and functional capacity in Chronic Obstructive Pulmonary Disease patients. Fisioter Mov. 2017;30(3):501-7.

Received: 02/18/2020

Recebido: 18/02/2020

Approved: 05/31/2020

Aprovado: 31/05/2020 